\title{
The Effects of Prolonged Sitting in a Cross-legged Posture on Pulmonary Function in Young Adults
}

\author{
Sung-Min Son \\ Department of Physical Therapy, College of Health Science, Cheongju University, Cheongju, Korea
}

Purpose: The impact of prolonged sitting in a cross-legged posture on physiological factors has not been extensively studied. We therefore attempted to evaluate whether prolonged sitting in a cross-legged posture affects pulmonary function in normal young adults. Methods: Twenty-four participants were recruited in this study, and the participants were equally allocated to the normal sitting posture group (NSP group, $n=12$ ) or sitting posture with the cross-legs group (SPCL group, $n=12$ ). The NSP group sat on chairs without crossing their legs for 30 minutes, and the SPCL group sat on the chair with legs crossed (the right knee on the left knee or the left knee on the right knee) for 30 minutes. The pulmonary function of the subjects was evaluated based on forced vital capacity (FVC), forced expiratory volume in one second (FEV1), FVC/FEV1, and peak expiratory flow (PEF) measured using a spirometer.

Results: In the intra-group comparison, the SPCL group showed significant differences in FVC and FEV1 before and after sitting $(p<0.05)$, but no significant differences $(p>0.05)$ were observed in the NSP group. However, there were no significant differences between the two groups in the pulmonary function parameters measured before and after sitting $(p>0.05)$.

Conclusion: Our results confirmed that prolonged sitting in a cross-legged posture could have a negative influence on pulmonary function. Therefore, if a sitting position is maintained for a long time, the correct sitting posture should be maintained to prevent musculoskeletal disorders as well as to maintain normal pulmonary function.

Keywords: Prolonged sitting, Cross-legged posture, Pulmonary function

\section{서 론}

앉기는 가장 일반적으로 몸을 움직이지 않는 정적 행동이며(sedentary behavior), 장시간 앉은 자세는 사람들의 건강에 부정적인 영향을 줄 수 있다. 하루 일과에서 앉은 시간이 많아질수록 심혈관계 질환, 당뇨와 조기 사망을 증가시킨다고 하였다.-4 그리고, 장시간 앉기 자 세를 유지하는 것은 내적인 건강 요인에 부정적인 영향을 줄 뿐만 아 니라 근골격계 요인들에도 악영향을 미친다.5, 선행연구들에서 앉아 서 업무를 위해 소비하는 시간과 요통의 강도(intensity of low back pain) 사이에 양의 상관관계를 가지고 있다고 보고하였고, ${ }^{7}$ 다른 연구 들에서도 장시간 앉은 자세는 다양한 근골격계 질환 발생과 관련되 어 있다고보고하였다. ${ }^{5-7}$

하루 동안 장시간 앉은 자세를 유지하는 시간이 많아지면서, 많은 사람들이 한쪽 다리를 다른 쪽 다리 무릎 위에 놓고 있는 다리 꼬은 자세(cross-legged posture)로 앉아 있는 것을 자주 발견할 수 있다. 다
리 꼬은 자세는 양쪽 골반의 높이 차이를 보상하기 위해서 사용하지 만, 대부분은 다리 꼬은 자세가 편하거나 습관적으로 익숙해진 경우 이다. 하지만, 앉은 자세와 함께 한쪽 다리를 꼬는 것은 신체의 근골 격계에 다양한 문제를 유발시킬 수 있다. ${ }^{9}$

앉은 자세는 시상면(sagittal plane)에서 척추 만곡(spine curvature) 의 변화를 유발하며, 장시간 앉은 자세를 유지할 경우 허리 척추주위 의 근육, 인대와 척추사이원반(intervertebral disc)에 기계적인 부하 (mechanical stress)가 증가될 수 있다.10,11 앉은 자세와 함께 다리 꼬는 자세는 시상면에서 척추 만곡의 변화와 더불어 수평면과 이마면에서 의 자세 및 모멘텀의 변화를 유발시킬 수 있다. 한쪽 다리를 꼬아 앉 은 자세를 유지하기 위해서는 한쪽 엉덩관절의 굽힘과 모음이 필요 하고, 이는 골반을 한쪽 방향으로 회전시켜 허리뼈를 비롯한 척추 전 체에 회전 모멘텀을 증가시키게 된다. ${ }^{12}$ 추가적으로 한쪽 다리를 꼬은 자세로 인해 양쪽 골반의 경사는 비대칭적인 위치가 되며, 이는 양쪽 엉덩 부위에 비대칭적인 압력이 가해져 척추측만증(scoliosis)과 같이 
척추를 정렬시킨다. ${ }^{33}$ 이러한 척추의 회전과 부적절한 정렬은 척추 주 위 근육들의 길이를 변화시켜 근력 발생에 부정적 영향을 줄 수 있 다. ${ }^{14}$ 또한, 허리뼈(lumbar vertebrae)는 수직 방향으로 가해지는 부하 에는 강하지만, 회전력에 의한 부하에는 취약하여 지속적으로 다리 를 꼬은 자세를 장시간 유지할 경우 허리 통증을 유발시킬 수 있다..$^{15}$

현대인의 삶은 움직임이 줄어든 양상으로 앉아서 더 많은 시간을 보내고 있고, 그래서 장시간 앉은 자세가 인체의 미치는 영향을 확인 하는 것은 중요하다. 지금까지 다리 꼬은 자세와 관련한 선행 연구들 은 대부분 등허리 영역(thoracolumbar area) 혹은 골반의 경사 각도와 체간 중심 근육들(core muscles)의 근활성도에 변화를 비교한 연구가 대부분이며, Ahn 등13의 연구에서는 다리 꼬은 자세로 인한 신체 정 렬의 변화는 등뼈(thoracic vertebrae)의 폄과 허리뼈의 굽힘을 제한시 켜 가슴벽(chest wall)의 움직임을 감소시킬 수 있다고 보고하였다. 하 지만, 이러한 변화로 인해 나타날 수 있는 호흡 기능과 같은 신체적 기 능 변화에 대한 연구는 없었다. 그래서, 우리의 연구에서는 다리 꼬은 자세가 호흡 기능에 미치는 영향을 확인하기 위해서, 장시간 유지할 경우 일반적인 앉기 자세와 다리 꼬는 자세를 유지하며 앉은 자세에 따라 호흡 기능에 차이가 있는지 확인하였다.

\section{연구 방법}

\section{1. 연구대상}

본 연구는 24 명의 젊은 남.녀 성인을 대상으로 실시하였다. 본 연구에 서 무작위 선정을 통해 전체 대상자들을 앉은 자세 방식에 따라 일반 앉기 그룹(normal sitting posture group, NSP group)과 다리 꼬고 앉기 그룹(sitting posture with cross-legged group, SPCL group)으로 구분하 였고, 각 그룹에 12 명씩 대상자들이 배정되었다. 실험 전에 연구의 목 적과 과정에 대하여 대상자에게 충분히 설명하였고, 실험 내용을 이 해하고 참여에 동의한 대상자들만으로 진행하였다. 대상자의 선별 기준은 다음과 같다. 1) 척추의 근골격계 혹은 신경학적 질환이 없는 자, 2) 호흡기계 혹은 심혈관계 질환이 없는 자, 3) 최근 6개월 이내에 흡연을 하지 않은 자로 하였다.

\section{2. 측정 도구 및 방법}

중재 전-후 대상자들의 호흡 기능을 평가하기 위해 폐기능측정 장비 (Micro Quark USB, Cosmed Ltd, Italy)를 사용하여 확인하였다. 폐기능 측정 장비를 통해 노력성 폐 용량(forced vital capacity, FVC), 1초간 노 력성 날숨 용적(forced expiratory volume in 1 second, FEV1) 및 최대 날 숨 유량(peak expiratory flow, PEF)을 측정하여 호흡 기능을 확인하였 다. 호흡 기능 능력을 측정하기 이전 대상자들에게 검사 방법에 대해 서 충분히 설명을 설명하였고, 검사자가 먼저 직접 시범을 보였다. 모
든 대상자들에게 2 번의 연습을 실시한 후 본 평가를 실시하였다.

호흡 기능 능력을 평가하기 위해 대상자들은 오금 높이에 의자 높 이를 맞추어 앉은 자세에서 실시하였고, 시선은 정면을 향하고 허리 를 곧게 편 상태에서 평가하였다. 대상자들은 허파 기능 측정 장비와 연결된 1 회용 마우스를 입에 물고 검사자의 신호에 맞추어 호흡을 실 시하도록 하였다. 호흡 기능 평가 시 대상자들은 검사자의 신호와 함 께 평상시 호흡을 3-4회 정도 실시한 후 가능한 최대로 강하게 숨을 들이마시고 최대한 빠른 속도와 함께 강하게 숨을 내쉬도록 지시하 였다. 중재 전-후 호흡 기능을 각각 3 번씩 측정하여 평균값을 사용하 였으며, 측정 사이에 30 초간의 휴식을 주었다.

\section{3. 실험절차}

일반적으로 장시간 앉기는 움직임이 최소화된 상태에서 30 분 이상 앉은 자세를 유지하는 것을 말하며, ${ }^{16}$ 본 연구에서는 두 그룹 모두 30 분 동안 앉은 자세를 유지하도록 하였다. 앉기 방식에 따른 두 그룹 사이에 중재 전-후 호흡 능력의 변화를 비교하기 위해 두 그룹 모두 중재 전 호흡 능력을 측정하였고, 30 분 앉기가 끝난 후 바로 호흡 능 력을 측정하였다. NSP 그룹은 양쪽 다리 모두 무릎관절이 $90^{\circ}$ 정도 굽힘 되어 30 분 동안 의자에 앉은 자세를 유지하도록 하였다. SPCL 그 룹은 무릎관절이 $90^{\circ}$ 굽힘 된 한쪽 다리 허벅지 위에 다른 쪽 다리 허 벅지가 올라가는 다리 꼬는 자세를 취하도록 하였으며(한쪽 무릎 위 에 다른 쪽 무릎이 올라감), 동일하게 30 분 동안 앉은 자세를 유지하 도록 하였다. 두 그룹 모두 앉은 자세를 유지하는 동안 두 발은 최대 한 붙이고 유지하도록 지시하였고, 상지와 체간은 편하게 자세를 취 할 수 있도록 움직임을 허용하였다. 장시간 앉은 자세를 취하는 동안 모든 대상자들에게 동일한 영상을 시청하도록 하였다. 실험에 사용 된 의자는 등받이가 부착되어 있으며, 대상자들의 다리 길이에 맞게 높낮이가 조절되는 의자를 사용하였다. 대상자들이 앉아 있는 동안 의자의 움직임을 최소화시키기 위해서 의자 다리 부위에 미끄럼 방 지 패드를 부착하였다.

\section{4. 자료분석}

수집된 자료의 통계 분석은 윈도우 SPSS 22.0 버전을 사용하여 실시 하였다. 두 그룹 사이에 대상자의 일반적 특성은 기술 통계와 독립 t검정을 이용하여 비교하였다. Shapiro-Wilk 검정을 사용하여 정규성 검정을 실시하였다. 두 그룹 사이에 중재 전. 후 호흡 능력의 변화를 비교하기 위하여 이요인 반복 측정 분산분석(two-way repeated-measures analysis)을 사용하여 확인하였고, 그룹 내 비교를 위해서는 대응 표본 $\mathrm{t}$ 검정(paired t-test)으로 확인하였다. 통계학적 유의 수준은 $\mathrm{p}<0.05$ 로 설정하였다. 
Table 1. The general characteristics of subjects

\begin{tabular}{lccc}
\hline & $\begin{array}{c}\text { NSP group } \\
(\mathrm{n}=12)\end{array}$ & $\begin{array}{c}\text { SPCL group } \\
(\mathrm{n}=12)\end{array}$ & $\mathrm{p}$ \\
\hline Male/Female & $4 / 8$ & $4 / 8$ & \\
Age $(\mathrm{yr})$ & $20.6 \pm 1.1$ & $20.3 \pm 1.2$ & 0.590 \\
Height $(\mathrm{cm})$ & $165.3 \pm 7.1$ & $164.5 \pm 8.6$ & 0.818 \\
Weight $(\mathrm{kg})$ & $60.2 \pm 12.9$ & $59.7 \pm 11.2$ & 0.920 \\
\hline
\end{tabular}

Mean \pm SD

NSP: normal sitting posture group, SPCL group: sitting posture with cross-legged group.

\section{결 과}

본 연구에 참여한 대상자들은 NSP 그룹과 SPCL 그룹으로 나누었으 며, 각 그룹에 12 명씩 전체 24 명으로 구성되었다. 두 그룹 사이의 일반 적 특성인 나이, 키, 몸무게에서는 통계학적으로 유의한 차이가 없었 다 $(\mathrm{p}>0.05)$ (Table 1).

중재 전·후 두 그룹 사이에 호흡 능력의 종속변수들(FVC, FEVl, $\mathrm{FEV1} / \mathrm{FVC}, \mathrm{PEF})$ 에서 시간 $\times$ 중재에 따른 상호 작용에서는 유의한 차 이가 나타나지 않았다(p>0.05). 그룹 내 비교에서 SPCL 그룹은 FVC 와 FEV1 호흡 기능에서는 유의한 차이가 있었지만 $(\mathrm{p}<0.05), \mathrm{FEV} 1 /$ $\mathrm{FVC}$ 와 PEF의 호흡 기능에서는 유의한 차이가 없었다( $>>0.05)$. NSP 그룹에서는 그룹 내 비교에서 모든 호흡 종속변수들에서 유의한 차 이가 없었다 $(\mathrm{p}>0.05)$ (Table 2).

\section{고 찰}

본 연구에서는 다리를 꼬고 장시간 앉기 자세가 호흡 기능에 미치는 영향을 확인하기 위해 정상적인 앉기 방법과 다리를 꼬고 앉기 방법 에 따라 두 그룹으로 나누었으며, 두 그룹 모두 30 분 동안 앉기 자세 를 유지하기 전과 후의 호흡 변화를 비교하였다. 본 연구의 결과는 정 상적인 앉기 방법과 다리 꼬고 앉기 방법에 따른 그릅 내 비교에서 $\mathrm{SPCL}$ 그룹에서 FVC와 FEV1에서 유의한 호흡 기능의 감소를 확인하 였고, NSP 그룹에서는 모든 호흡 변수에서 유의한 변화를 확인할 수 없었다. 하지만, 두 그룹 간 비교에서 모든 호흡 변수에서 유의한 차이 가 없었다.

우리의 연구는 SPCL 그룹에서 FVC와 FEV1와 같은 호흡 기능에서 감소가 나타났으며, 이는 다리 꼬고 장시간 앉기 방법이 호흡 기능에 부정적인 영향을 줄 수 있는 요인임을 확인한 결과라 생각한다. 지금 까지 한쪽 다리를 꼬은 자세가 생리학적 요소에 미치는 영향을 확인 한 연구가 미흡하여 호흡기능을 감소시킨 정확한 기전을 제시할 수 는 없다. 하지만, 다리 꼬은 자세가 호흡 기능을 감소시킨 요인에 대해 고려해 볼수 있는 기전이 있다.
Table 2. Comparison of pulmonary in between the NSP and SPCL group

\begin{tabular}{lccc}
\hline Parameter & $\begin{array}{c}\text { NSP group } \\
(\mathrm{n}=12)\end{array}$ & $\begin{array}{c}\text { SPCL group } \\
(\mathrm{n}=12)\end{array}$ & $\begin{array}{c}\text { Time } \times \text { Group } \\
{ }^{+}\end{array}$ \\
\hline FVC (L) & & & 0.367 \\
Pre & $3.64 \pm 0.85$ & $3.62 \pm 0.88$ & \\
Post & $3.55 \pm 0.82$ & $3.48 \pm 0.92$ & \\
p-value & 0.182 & $0.001^{*}$ & \\
Post-Pre & $-0.080 \pm 0.195$ & $-0.138 \pm 0.11$ & \\
FEV1 (L) & & & 0.622 \\
Pre & $2.86 \pm 0.92$ & $2.75 \pm 0.95$ & \\
Post & $2.82 \pm 0.96$ & $2.68 \pm 1.00$ & \\
p-value & 0.430 & $0.038^{*}$ & \\
Post-Pre & $-0.046 \pm 0.19$ & $-0.078 \pm 0.11$ & \\
FEV1/FVC (\%) & & & 0.971 \\
Pre & $77.71 \pm 10.00$ & $75.49 \pm 12.94$ & \\
Post & $77.91 \pm 12.29$ & $75.75 \pm 11.95$ & \\
p-value & 0.848 & 0.838 & \\
Post-Pre & $0.20 \pm 3.53$ & $0.25 \pm 4.28$ & \\
PEF (L) & & & 0.417 \\
Pre & $4.87 \pm 2.30$ & $4.95 \pm 1.84$ & \\
Post & $4.81 \pm 2.12$ & $4.77 \pm 1.75$ & \\
p-value & 0.606 & 0.133 & \\
Post-Pre $^{+}$ & $-0.05 \pm 0.35$ & $-0.18 \pm 0.38$ & \\
\hline
\end{tabular}

Mean \pm SD

NSP: normal sitting posture group, SPCL group: sitting posture with cross-legged group.

${ }^{*}$ significant difference between pre and post-test $(p<0.05)$, ${ }^{+}$two-way repeatedmeasures analysis, ${ }^{\ddagger}$ paired t-test.

우선 다리를 꼬고 앉기는 정상적인 앉기 방법과 비교했을 때, 척추 정렬을 포함한 신체의 변화를 발생시킬 수 있다.12.13,17 $\mathrm{Ahn}$ 등 ${ }^{13}$ 의 연구 에서는 다리 꼬고 앉은 자세가 정상적인 앉기 자세보다 등과 허리 척 추들(the lumbar and the thoracic spines)에서 척추 뒤굽음 증가와 골반 의 뒤쪽 기울임을 더욱 증가시킬 수 있다고 보고하였다. 이러한 척추 정렬의 변화는 자세를 더욱 구부정한 앉은 자세(slumped sitting posture)로 야기시킬 수 있다. 선행 연구에서 장시간 구부정한 앉은 자세 는 허리빼(lumbar vertebrae) 주위의 수동적인 구조물들의 뺏뻣함 (stiffness)을 증가시킬 수 있다고 하였고 ${ }^{18}$ Callaghan과 $\mathrm{MaGill}{ }^{19}$ 의 연 구에서는 허리뼈 굽힘에 수동적인 저항을 제공하는 구조물들의 점 탄성 변화는 척추의 움직임 범위를 감소시킬 수 있다고 하였다. 이와 함께 등빼(thoracic vertebrae) 척추들의 뒤굽음 증가는 갈비빼(rib) 사 이 공간을 좁히며, 장시간 동안 좁아진 상태로 유지할 경우 갈비 사이 공간에 있는 구조물들은 탄력성이 감소되거나 뺏뻣함이 증가되어 체간의 움직임이 감소될 수 있다. ${ }^{20} J o h a r i$ 등 21 의 연구에서 등빼 척추 의 뒤굽음과 $\mathrm{FVC}$ 사이에는 음의 상관 관계가 있으며, Rahman ${ }^{22}$ 의 연 구에서도 등뼈 척추의 뒤굽음증이 증가된 노인들에서 호흡기능과 음의 상관관계가 있음 보고하였다. 이는 척추 뒤굽음 증가 시 노력성 
날숨 용적의 감소를 유발시킬 수 있음을 확인한 연구로서 우리의 연 구를 뒷받침한다. 장시간 동안 구부정한 앉은 자세로 인한 척추의 구 조물들의 탄력성 감소와 뻣뺏함의 증가는 체간의 비효율적인 움직임 과 가로막의 움직임을 제한시켜 호흡 기능의 감소에 기여한 것으로 생각된다.

두번째로 허리-골반 근육들은 척추의 상부 허리뼈 부위에 가해지 는 압박력에 대해 균형을 맞추고 앉는 기간 동안 허리의 안정성을 증 가시키기 위한 국소 시스템으로 작용하고, 잘못된 자세는 허리-골반 근육들의 피로도 증가와 근육 약화를 유발시킬 수 있다.10,23 선행 연 구에서 골반의 뒤쪽 기울임 증가는 뭇갈래근과 척추세움근(가시근) 뿐만 아니라 복부 근육들의 활성화를 감소시킨다고 보고하였다.10 앞 에서 언급했듯이, 다리를 꼬고 앉은 자세는 척추의 정렬을 더욱 구부 러진 자세로 유발시킬 수 있으며, ${ }^{13,24}$ 다리를 꼬고 장시간 앉은 자세를 유지하는 자세에서도 허리 부위의 뭇갈래근과 배빗근(lumbar multifidus and oblique muscles) 같은 허리-골반 근육의 피로가 증가될 수 있다고 하였다. ${ }^{25}$ Waongenngarm 등 26 의 연구에서도 장시간 동안 구부 러진 앉은 자세를 유지할 경우 배속빗근(internal oblique)과 배가로근 (transversus abdominis)의 근활성도가 감소가 나타났다고 보고하였 다. 배속빗근을 포함한 복부 근육들(abdominal muscles)은 호흡에서 중요한 역할을 담당한다. 복부 근육들은 안정 시 호흡시에는 일반적 으로 활동이 거의 없지만, 강한 운동이나 노력성 들숨과 날숨 호흡 동안에 주로 작용하여 호흡 기능에 영향을 준다. $2728 \mathrm{Gollee}$ 등 29 의 연 구에서 복부 근육들을 강화시키는 자극은 호흡 능력을 향상시켰다 고 보고하였으며, 이는 복부 근육의 약화 혹은 피로는 호흡 능력을 감소시킬 수 있음을 시사한다. 본 연구에서도 호흡 기능을 평가하기 위해서 노력성 폐활량들을 측정하였으며, SPCL 그룹의 호흡 능력 감 소는 장시간 다리를 꼬고 앉은 자세로 인해 발생한 복부 근육들의 피 로도가 호흡 기능에 영향을 준 것이라 사료된다.

우리의 연구 결과에서 앉은 자세로 장시간 동안 다리 꼬는 자세를 유지하는 것은 호흡 기능에 부정적인 영향을 주는 요인으로 작용할 수 있음을 확인하였다. 따라서, 장시간 동안 앉은 자세를 유지하는 경 우 근골격계 질환의 예방뿐만 아니라 정상적인 호흡 기능을 유지하 기 위해 올바른 앉기 자세가 이루어져야 할 것이다. 또한 우리의 연구 결과는 다양한 임상 현장에서 장시간 다리 꼬는 자세로 인해 발생할 수 있는 부정적인 영향에 대한 근거를 제공한다고 할 수 있다. 하지만, 본 연구의 결과에는 고려해야 할 몇 가지 제한점이 있다. 첫째, 우리의 연구는 여러 다리 꼬고 앉기 방법 중 한 가지 방법만을 선택하여 다 른 다리 꼬고 앉기 방법들을 고려하지 못했다. 둘째, 연구의 대상자 수가 적고, 젊은 성인들만 대상자로 선정하여 일반화하기 어려움이 있다. 앞으로의 연구는 이러한 여러 제한점들을 보완하여 추가적인 연구들이 이루어져야할 것이다.

\section{REFERENCES}

1. Hamilton MT, Healy GN, Dunstan DW et al. Too little exercise and too much sitting: inactivity physiology and the need for new recommendations on sedentary behavior. Curr Cardiovasc Risk Rep. 2008;2(4):2928 .

2. Gill JM, Cooper AR. Physical activity and prevention of type 2 diabetes mellitus. Sports Med. 2008;38(10):807-24.

3. Thompson PD. Exercise and physical activity in the prevention and treatment of atherosclerotic cardiovascular disease. Arterioscler Thromb Vasc Biol. 2003;23(8):1319-21.

4. Lollgen H, Bockenhoff A, Knapp G. Physical activity and all-cause mortality: an updated meta-analysis with different intensity categories. Int J Sports Med. 2009;30(3):213-24.

5. Katz JN. Lumbar disc disorders and low-back pain: socioeconomic factors and consequences. J Bone Joint Surg Am. 2006;88(2 Suppl):21-4.

6. Waongenngarm P, Rajaratnam BS, Janwantanakul P. Perceived body discomfort and trunk muscle activity in three prolonged sitting postures. J Phys Ther Sci. 2015;27(7):2183-7.

7. Park SM, Kim HJ, Jeong HS et al. Longer sitting time and low physical activity are closely associated with chronic low back pain in population over 50 years of age: a cross-sectional study using the sixth Korea national health and nutrition examination survey. Spine J. 2018;18(11):2051-8.

8. Jung KS, Jung JH, In TS. The effects of cross-legged sitting on the trunk and pelvic angles and gluteal pressure in people with and without low back pain. Int J Environ Res Public Health. 2020;17(13):4621.

9. Gimson M. Weight distribution in sitting and the effect of leg-crossing. Physiotherapy. 2003;89(2):125.

10. Morl F, Bradl I. Lumbar posture and muscular activity while sitting during office work. J Electromyogr Kinesiol. 2013;23(2):362-8.

11. Szczygie $\Varangle$ E, Zielonka K, Męte S et al. Musculo-skeletal and pulmonary effects of sitting position-a systematic review. 2017;24(1):8-12.

12. Schamberger $\mathrm{W}$. The malalignment syndrome: implications for medicine and sport. London, Churchill Livingstone, 2002:456.

13. Ahn SJ, Kim SH, Kang SY et al. Asymmetrical change in the pelvis and the spine during cross-legged sitting postures. J Korean Med Sci. 2013; 27(11):3427-32.

14. Andersson BJ, Ortengren R, Nachemson AL et al. The sitting posture: an electromyographic and discometric study. Orthop Clin North Am. 1975; 6(1):105-20.

15. Kim MJ, Son CG, Heo DS et al. Analysis of clinical tendency of spinal disorder in primary, middle and high school students in Korea. J Acupunct Res. 2010;27(2):43-9.

16. Dunstan DW, Wiesner G, Eakin EG et al. Reducing office workers' sitting time: rationale and study design for the stand up victoria cluster randomized trial. BMC Public Health. 2013;13(1):1-14.

17. Andersson B, Ortengren R, Nachemson AL et al. The sitting posture: an electromyographic and discometric study. Orthop Clin North Am. 1975; 6(1):105-20.

18. Beach TA, Parkinson RJ, Stothart JP et al. Effects of prolonged sitting on the passive flexion stiffness of the in vivo lumbar spine. Spine J. 2005;5 (2):145-54.

19. Callaghan JP, MaGill SM. Low back joint loading and kinematics during standing and unsupported sitting. Ergonomics. 2001;44(3):280-94. 
20. Culham EG, Jimenez HA, King CE. Thoracic kyphosis, rib mobility, and lung volumes in normal women and women with osteoporosis. Spine. 1994;19(11):1250-5

21. Johari J, Sharifudin MA, Ab Rahman A et al. Relationship between pulmonary function and degree of spinal deformity, location of apical vertebrae and age among adolescent idiopathic scoliosis patients. Singapore Med J. 2016;57(1):33-8.

22. Rahman NN, Singh DK, Lee R. Correlation between thoracolumbar curvatures and respiratory function in older adults. Clin Interv Aging. 2017;12:523-9.

23. Le P, Marras WS. Evaluating the low back biomechanics of three different office workstations: seated, standing, and perching. Appl Ergon. 2016;56:170-8

24. Yu JS, An DH. Differences in lumbar and pelvic angles and gluteal pressure in different sitting postures. J Phys Ther Sci. 2015;27(5)1333-5.
25. Harrison DD, Harrison SO, Croft AC et al. Sitting biomechanics part I: review of the literature. J Manipulative Physiol Ther. 1999;22(9):594609.

26. Waongenngarm P, Rajaratnam BS, Janwantanakul P. Internal oblique and transversus abdominis muscle fatigue induced by slumped sitting posture after 1 hour of sitting in office workers. Saf Health Work. 2016; 7(1):49-54.

27. Hides JA, Richardson CA, Jull GA. Multifidus muscle recovery is not automatic after resolution of acute, first-episode low back pain. Spine. 1996;21(23):2763-9.

28. Abe T, Kusuhara N, Yoshimura N et al. Differential respiratory activity of four abdominal muscles in humans. J Appl Physiol. 1996;80(4):1379-89.

29. Gollee H, Hunt KJ, Fraser MH. Abdominal stimulation for respiratory support in tetraplegia: a tutotial review. J Autom Contr. 2008;18(2):8592. 